\title{
Integration and exclusion at work: Latvian and Swedish agency nurses in Norway
}

Hege Merete Knutsen, Katrine Fangen and Oksana Žabko

This is a post-peer-review, pre-copyedit version of an article published in Journal of

International Migration and Integration. The final authenticated version is available online at: https://doi.org/10.1007/s12134-019-00660-5

\begin{abstract}
Qualitative interviews with Latvian and Swedish agency nurses in Norway reveal that the two groups have quite different experiences of integration in the Norwegian labour market.

Aiming to add knowledge about differentiation within migrant labour markets, the objective of this article is to examine how language, nursing culture and personal motivation affect the double control that agency nurses are subject to, their resultant skill-sets, inclusion in the workplace and response to this. Norway is of interest as the Norwegian language can be difficult to learn outside Scandinavia. The Latvian agency nurses are harder hit by the double control of the temporary work agencies than the Swedish are. They obtain higher wages and better working conditions and are ready to speak up against unfair treatment. If they want to leave the agency, they easily find direct employment. Latvian nurses seem more ready to accept work below their qualifications and some show signs of 'resigned acceptance'. They have more to lose than the Swedish nurses in terms of access to work, wages and working conditions if they return to their homeland. Although Latvian and Swedish nurses largely feel well received in the workplace, the double control they are subject to calls for self-restraint and impedes a sense of inclusion. For the Latvian nurses, language problems and cultural differences exacerbate this. The study expands and nuances how double control affects agency workers, and applying a broad concept of resigned acceptance it nuances what language means for discrimination in the workplace.
\end{abstract}

Keywords: agency nurses, de-skilling, double control, migrant nurses, Norway, resigned acceptance

\section{Introduction}

Several studies have identified language problems and culture differences as obstacles to labour market integration for migrant nurses (see Allan and Westwood 2016; Hull 2016; 
Primeau et al. 2014). Based on qualitative interviews with Latvian and Swedish agency nurses in Norway, we find that the two groups have quite different experiences of integration in the Norwegian labour market. Aiming to add knowledge about differentiation within migrant labour markets, the objective of this article is to examine how language, nursing culture and personal motivation affect the double control that foreign agency nurses are subject to and their resultant skill-sets, workplace inclusion and response to this. Double control refers to the situation of being subject to a double layer of management and sanctions, i.e. at the agency level and in the workplace (Gottfried 1991, 1992).

The article builds on a case-study approach, using qualitative interviews with 11 Latvian and 20 Swedish nurses, with agencies in Norway and Latvia and with hospital-sector employers. Norway is of interest, firstly because wages and working conditions for nurses in Norway are relatively good compared with other countries; secondly because the Norwegian language can be difficult to learn outside Scandinavia. Despite some differences, Norwegian and Swedish are generally mutually comprehensible.

The Norwegian health sector is predominantly public. It employs some 95000 nurses (Statistics Norway 2016), but is currently short of 4000 (NAV 2017). Permission to work as a registered nurse requires individual authorization from the Norwegian Directorate of Health. It is difficult to recruit nurses to fill vacant positions both in the public health enterprises (hospitals) and in the municipal sector (nursing homes and homecare). ${ }^{1}$ Norwegians tend to avoid the nursing profession, due to the low wages compared to other economic sectors, understaffing and inconvenient shift-work (NSF 2018; Skjøstad et al. 2017). There is also a need for substitute nurses because of sick leave, parental leave and holiday seasons (Gautun et al. 2016). Already in the late 1990s, the Norwegian government recruited nurses in Finland, Poland and the former Eastern Germany to fill vacancies (Widding Isaksen 2012). In 2001, all sectors of the Norwegian economy were opened to private agencies, and since then, agencies have played an important role in providing nursing personnel for health institutions.

Ever since 2006, Swedish nurses have constituted the largest group of foreign nurses in Norway (Berge et al. 2011). Although fewer than Swedish nurses, the number of Latvian nurses in Norway increased from 63 to 207 from 2010 to 2014, and further from 242 to 255 from 2015 to 2016 (Statistics Norway, personal communication). ${ }^{2}$ In addition comes an

\footnotetext{
${ }^{1}$ A few private actors operate in nursing homes and homecare in the municipal health sector, acting on behalf of the municipality.

${ }^{2}$ The figures include directly employed nurses and nurses working for agencies based in Norway, and they refer to a representative week in November.
} 
unknown number of Latvian nurses employed by agencies that are not based in Norway. Higher wages, better-regulated working hours and lower workload emerged the main reasons why our Latvian and Swedish respondents sought employment in Norway. Differences were especially pronounced for Latvian nurses, as Norwegian wage levels for nurses are roughly six times higher than in Latvia. ${ }^{3}$ From 2015, it became increasingly difficult to recruit Swedish nurses to Norway, due to the higher wages and summer bonuses in Sweden for those willing to postpone their holidays, and to the depreciation of the Norwegian krone (Kiil and Knutsen 2016). Health institutions and agencies have thus intensified their efforts to recruit nurses from other countries, also those with languages and nursing cultures quite different from Norwegian/Swedish.

The article continues with a literature review and presentation of our key concepts, followed by a section on methodology and presentation of the data material. The first part of the analysis addresses the first layer of double control: We examine the role of the agencies in providing and controlling access to the Norwegian labour market and the response of the nurses. The second part examines how the nurses experience and respond to possible downgrading and de-skilling in the workplace where the second layer of double control plays out. The third part delves more specifically into the role of language for inclusion and exclusion in the workplace and what it tells us about the double control of the nurses. In the conclusion, we explain our findings in light of differences in language, nursing culture, personal motivations and the nature of agency nursing, before we point out how our findings contribute to existing literature.

\section{Literature review and conceptual framework}

Studies of migrant nurses note problems related to the lack of fluency in the dominant host language (see Allan and Westwood 2016; Hull 2016; Primeau et al. 2014). For reasons of patient safety, nurse-patient relations, teamwork, and overall quality of health service, nurses need a good command of everyday language and medical terminology in the receiving country (Hull 2016; National Nursing Research Unit 2014).

Medical language varies from country to country, including jargon and abbreviations used. In addition, come the problems of local dialects and accents. Foreign nurses need time to

\footnotetext{
${ }^{3}$ In 2015, average monthly wage for non-specialized nurses in Norway was NOK 41100 (EUR 4591); for specialized nurses, it was NOK 44500 (EUR 4970) (Statistics Norway, 2017) In Latvia, average gross monthly wage for specialist nurses was 759.80 EUR in December 2016 and 729.30 EUR in December 2015 (Central Statistical Bureau of Latvia, 2017).
} 
acquire language skills, but the language training offered is not always satisfactory (Hull 2016; Jose 2010; Marcus et al. 2014). Ideally, the first step should be to acquire intermediate to advanced skills in everyday language, and then focus fully on medical terminology (Hull 2016). Language learning involves acquiring not only a functional vocabulary, but also cultural competence and an understanding of how language is used in context (Hull 2016; Magnusdottir 2005).

Foreign nurses experience stress and fear of compromising patient safety, as well as disempowerment and isolation, due to lack of fluency in the dominant host language (Magnusdottir 2005; O’Neill 2011). Unease continues when they start to master the foreign language: they worry that colleagues may overestimate their language skills, with potential danger to patients (Magnusdottir 2005). Language problems can lead nurses to withdraw to a subordinate position. While some find it easier to talk with patients than with colleagues, other nurses, especially those from cultures with greater distance between nurses and patients, feel uncomfortable about the informal way patients are addressed, and opt to speak less (O’Neill 2011). The silence resulting from communication barriers is frustrating, and prevents nurses from using and demonstrating their skills; some even start to doubt their own expertise. Moreover, good communication skills make it easier to get jobs in the specialties where the nurses wish to work (Newton et al. 2012).

A recurrent theme in the literature on migrant nurses is how institutional discrimination impedes inclusion in the labour market. Institutional discrimination refers to 'embedded policy-based organizational or community actions that affect a subordinate group unfavourably’ (Tuttas 2015, p. 517), regardless of any intention to harm. In general, language can act as a proxy for direct discrimination (see Blackledge 2005; Shohamy 2009).

Discrimination of foreign nurses certainly occurs. For example, they may get lowerquality training, thus becoming ‘second-level’ nurses (Batnitzky and McDowell 2011). Immigrant nurses are often offered low-status jobs, perhaps in small, privately owned, unregulated nursing homes (Smith and Macintosh 2007). Many studies report factors like lower wages, pressures for undesirable shift-work, difficult access to training and promotion, and fears that not being able to practise their professional skills will lead to de-skilling (see Larsen 2007; Raghuram 2007; Smith and Mackintosh 2007; Tuttas 2015).

Previous studies on agency nursing argue that this can be a strategy to earn higher wages and escape inconvenient shifts and stressful working conditions as agency nurses tend to have fewer areas of responsibility than permanently employed nurses have. There are, however, stressful aspects of agency nursing such as unpredictability regarding access to work, many 
short-term assignments and worries of mistakes and litigations in unfamiliar workplaces (see De Ruyter et al. 2008; Tailby 2005). Other studies reveal how migrant agency nurses are exploited in the workplace in terms of wages, working hours, getting the worst shifts, being under graded and getting the most disadvantageous work and so on (see Buchan et al. 2005; Lloyd et al. 2014; Smith and Mackintosh 2007).

Agency workers are subject to a situation of double layer of management and sanctions (Gottfried 1991, 1992) or double control. In the case of the agency nurses, double control means that they are subject to requirements and control both of the agency that employs them and the health institution where they work. They have to live up to the expectations of both the agency and the health institution to get an assignment and a chance to return to the workplace. We therefore ask: How do differences in language, nursing culture and the personal motivations of the nurses affect the double control they are subject to, and what does this in turn tell us about the challenges of de-skilling, institutional discrimination and inclusion in the workplace.

Examining labour market integration, we are concerned with how agencies facilitate and control access to - or participation in - the Norwegian labour market. In this context, exclusion occurs when being expelled from the labour market or being denied access. Regarding what types of positions and quality of work that the nurses get, the health institutions play a greater role. As labour market 'integration in terms of holding a job does not necessarily preclude feelings of exclusion' (Fangen and Paasche 2013, p. 608), we apply the concepts of social exclusion and social inclusion examining how the agency nurses experience their working conditions with the agency and in the workplace. In this context too, we are concerned with access to positions and working conditions on par with what permanently employed nurses get. Further, exclusion varies "from overt racism to institutionalized ways of treating someone as 'different'”, (Fangen 2010: p. 136). The latter fits the concept of institutional discrimination (Tuttas 2015 above).

In the study of Batnitzky and McDowell (2011, p. 196), resigned acceptance refers to how nurses respond to institutional discrimination without resentment and rather focus on professional ethic and doing a good job knowing what they want to get out of life. Our point of departure is that resigned acceptance could be a response to any aspect of negative working conditions, and thus not necessarily discrimination, whether the alternative is considered worse or in anticipation of something better to come (delayed gratification). While inclusion is partly the opposite of exclusion, it also invokes a feeling of being valued, belonging and agreement on values, which also affects acceptance. We look into the following: What 
characterizes the work that the agency nurses do in terms of upgrading and downgrading of skills and do they feel valued and important.

\section{Methodology}

We are inspired by case studies as a research strategy as conceptualized by Yin (2014). While our study is empirical and explorative, our objective and questions are embedded in insights from previous research on temporary work agencies, and literature reviews on migrant nurses and their challenges with language, differences in nursing cultures, discrimination and coping strategies. The case of the Latvian nurses is our main case. The Swedish case is used as a contrast to the Latvian case to tease out a better understanding of what differences in language and nursing culture mean to how migrant temporary workers experience their conditions.

Our material consists of in-depth semi-structured interviews with Latvian (11) and Swedish (20) nurses, ${ }^{4}$ with representatives of agencies in Latvia (2) and Norway (2), managers in Norwegian health enterprises and hospitals (4), and trade union representatives in Latvia (1) and Sweden (1) (see Table 1).

Table 1. Interview overview

\begin{tabular}{|l|l|l|}
\hline & $\begin{array}{l}\text { Latvian } \\
\text { nurses }\end{array}$ & $\begin{array}{l}\text { Swedish } \\
\text { nurses }\end{array}$ \\
\hline Number of respondents & 11 & 20 \\
\hline Experience as agency nurse & 10 & 13 \\
\hline Agency nurse at the time of interview & 3 & 5 \\
\hline $\begin{array}{l}\text { Directly employed temporary nurse at time of } \\
\text { interview }\end{array}$ & 1 & 9 \\
\hline $\begin{array}{l}\text { Standard employment contract with a health inst. at } \\
\text { time of interview }\end{array}$ & 6 & 5 \\
\hline $\begin{array}{l}\text { Working in nursing home/homecare at time of } \\
\text { interview }\end{array}$ & 8 & 2 \\
\hline Working in hospital at time of interview & 2 & 15 \\
\hline No longer working in Norway & 1 & 3 \\
\hline
\end{tabular}

Note: One Swedish nurse combined standard employment with direct temporary employment in another health institution and one combined direct temporary employment with temporary agency work. Hence, the numbers of Swedish agency nurses, directly employed temporary nurses and nurses with standard employment contracts at the time of interview add up to 19 and not 17.

\footnotetext{
${ }^{4}$ Maiken Bjerga Kiil conducted the bulk of the interviews with the Swedish nurses, see also (reference to publication).
} 
As nursing is predominately a female occupation in Latvia, all the Latvian nurses interviewed were women. They ranged in age from mid-twenties to early fifties. One nurse had settled down in Norway, and was living together with her husband and child.

We interviewed the Latvian nurses over two time-periods: the first three nurses in 2015, and the remaining eight in 2016 and 2017. Five of the Latvian nurses were recruited through professional networks and six through Facebook. In selecting interviewees, we sought to cover a range of Latvian regions, various length of experience working in Norway (ranging from around 6 months to five to six years) and experience with Latvian agencies in obtaining work in Norway. Only one of the nurses had experience with Norwegian agencies.

The Swedish nurses were recruited through a hospital, the Internet and by the snowball method. Most interviews with Swedish nurses took place in 2014 and 2015. Although the Swedish data are somewhat older than the Latvian data, the comparison makes sense. They are still highly valued in the hospital sector and can use their position to improve their terms of employment (interview, head of hospital ward 2017).

All nurses were asked the same core questions on the role of agencies in accessing the Norwegian labour market, recruitment process and services provided by agencies, career path in Norway and working conditions in Norway compared with their homelands. A Latvian researcher interviewed the Latvian respondents in their native language and Norwegian researchers interviewed the Swedish and Norwegian respondents. Interviewing Swedish respondents in Norwegian had no particular impact on the flow of the interviews, as the two languages are very similar. We were all female interviewers and obtained a good rapport with the respondents. All of the respondents were informed about the purpose of the project and they were offered anonymity.

The Latvian interviews were transcribed in Latvian and then translated to English. The interviews with the Swedish nurses were transcribed in Norwegian and analyzed by Norwegians. Data and meaning could get lost in translations (see Young and Temple 2014). It is thus important to note that the Latvian interviewer is also one of the authors of this article.

There were no clear differences in the experiences of the Swedish nurses according to age and gender (four of the Swedish nurses were male) and whether they worked in the hospital sector or nursing home/home care sector, but none of them were working in particularly remote areas as the Latvian nurses do. The Latvian nurses also shared very similar experiences, but different from the Swedish nurses.

Inspired by the literature review, but still open to the unexpected, we conducted a mixture of inductive and deductive data analysis. We analyzed the data manually and independently, 
searching for aspects relating to discrimination, nursing culture, language, positive and negative aspects in the employment relationship with the temporary work agencies and positive and negative aspects concerning conditions in the workplace, motivations and strategies. Then we reconciled and summarized findings from our separate analyses.

\section{Between facilitation and double control}

Without an agency, getting employment in Norway would be difficult, and the Latvian and Swedish respondents alike were appreciative of the agencies as a channel into the Norwegian labour market. In the first layer of double control, both groups are subject to screening in the form of interviews. Then also get detailed information about what is required of them and how to represent the agency in the workplaces.

The Latvian agencies offer full-package services: language courses and testing, assistance with applications for authorization in Norway, and travel and accommodation. One agency also requires its Latvian nurses to pass a test of their psychological ability for teamwork and that they are open and positive, before they are selected for the language course.

The Latvian nurses must sign contracts of 1.5 to 2 years, to compensate the agencies for the language courses. Contract length varies somewhat and the nurses are not to have job offers, or downtime waiting for work, during the contract period. Contractual conditions have evolved as agencies learn from experience and sharpen their requirements. Currently, they do not permit a second job in Latvia, which makes Latvian nurses increasingly dependent on and controlled by these agencies.

The Latvian nurses earn less than Norwegian nurses, but do not complain. Their wages are much higher than in Latvia (footnote 3 above), and they cannot afford to pay privately for language courses, travel and accommodation:

I am not a fool. I realize that they [the agencies] make money thanks to us. I've heard that we receive less than the Norwegians. They [the agencies] deducted some percentages of our wages, and that's completely normal. If you compare wages you receive in Latvia and here, it is like night and day. To go on your own to Norway in the middle of nowhere, find somewhere to live, find somewhere to work, and with the cost of living so high - all that is unrealistic. (Latvian nurse 3)

However, the Latvian nurses were not able to explain on what basis their wages were calculated. One of the Latvian agencies offers entry wages in Norway that equals Norwegian wages with four years of work experience, no matter the length of work experience in Latvia. 
Some of the nurses in our sample started in Norway with up to twenty years of experience from Latvia, several years of service did not count.

Nurses who make mistakes or do not perform well lose their assignment or are not welcome back to the health institutions. In line with Gottfried (1991), this reflects badly on the agencies, and means that these nurses also risk losing their job with the agency as such. Nurses who do not pass the language test are excluded. Those who pass the test, but with difficulty, may have a long wait for their first assignment. That is problematic because they get little or no payment during downtime and in-between assignments. However, having invested in language training, agencies are generally helpful in finding new placements when beginners have problems or fail.

The Latvian nurses work between four weeks and three - four months at a time in Norway. Occasionally, agencies ask their Latvian nurses to spend a longer period in Norway during summer holidays than initially agreed: some nurses feel obliged to do so, while others feel free to refuse. Regarding overtime, both Latvian and Swedish agency nurses say that they have to work more hours than directly employed staff to get overtime compensation. ${ }^{5}$ Some complain that it has become more difficult to get double shifts and overtime, recalling how they used to get as much work as they wanted from the agencies. Regulations on overtime have become more strictly enforced in Norway, following incidents like the Adecco scandal in 2011 (see Lloyd et al. 2014), which revealed illegal working conditions in a nursing home.

The Latvian nurses say that the accommodation provided by the agencies varies in quality. 'We live like in a dormitory', said one. (Latvian nurse 11) How many nurses live together varies; the highest number mentioned was 20 . Some noted that the accommodation provided by the agencies has improved over time. The only complaint is that too many persons live together, which can be a mental strain.

The Swedish nurses complain more if they are not satisfied with the quality and cleanliness of their accommodation. An agency corroborates that recruiting Swedish nurses has become increasingly problematic: ' ...they come for shorter and shorter periods, and are more and more demanding and expensive.' Some nurses leave the agency because of the accommodation and wages. One nurse said: 'let me know when the accommodation is better'

The Swedish nurses know their worth, and have the necessary knowledge to manoeuvre strategically in the Norwegian labour market, swapping agencies if they are displeased or seek employment on their own (Zampoukos et al. 2018). Language/cultural and geographical

\footnotetext{
5 This could be explained by technicalities of the shift-work system.
} 
proximity make it relatively easy for the Swedish nurses to act independently. Those who continue to work for agencies find it convenient not to have to organize travel and accommodation when they go for short periods. The Swedish nurses often work for only 1012 days in Norway and want to get in as much work as possible before returning to Sweden. With direct employment relations, they may be able to work fewer hours to get overtime than with agencies. Moreover, the agency work schedule may not always be fully booked before they arrive - and payment is only for the hours actually worked.

Both the Latvian and the Swedish nurses report that agency work is stressful in the longer term, because of rapid shifts of workplaces and locations, and the travelling involved, which equal the experiences of agency nurses in other countries (see De Ruyter et al. 2008; Tailby 2005). The Latvian nurses, however, are stuck with their agencies until their contracts expire and they have compensated for the language training costs.

Although the Latvian data are in line with scholarship addressing the exploitative nature of agency nursing (Buchan et al. 2005; Lloyd et al. 2014; Smith and Macintosh 2007), the nurses report that they 'understand' and are 'appreciative' of the agencies (as Latvian nurse 3 above) and they do not complain. Their tight economy in Latvia, the comparatively high costs of living in in Norway and their strong dependence on the agencies for language training are reasons for this. The fact that they do not complain is thus a sign of resigned acceptance (Batnitzky and McDowell 2011).

\section{Downgrading, de-skilling and institutional discrimination?}

While most nurses in our sample had worked in the hospital sector in their homeland, the Swedish nurses got work in Norwegian hospitals. The Latvians ended up in the homecare and nursing-home sector, a sign of occupational downgrading. Moreover, at the time of our interviews, five of the eleven Latvian nurses were working in peripheral areas of Norway where it is particularly difficult to attract nurses (Table 1).

There was also an opportunity for a permanent job, but that involved taking three flights. A very long way to travel. I would not like to stay there. The colleagues were OK, yes, but very remote and the nearest shop is $5 \mathrm{~km}$ away. Not the place of my dreams. I left it of my own volition. (Latvian nurse 5)

According to the international literature on nursing, a segmented labour market and hierarchal order of employment could be signs of institutional discrimination (Batnitzky and McDowell 2011; Smith and Macintosh 2007; Tuttas 2015). The Latvian nurses, however, do not report 
feeling discrimination in this sense. They say that they are satisfied with their current positions and that they cannot get better jobs due to language problems. Many see their work in Norway as 'different' or as involving 'wider duties' because they need time to adapt to a new environment and different ways of working. One explained that working in a nursing home was fine because she no longer had high ambition:

I work in a nursing home, yes. It might be possible to work in a hospital, of course. If I were 30 years old, I wouldn't want to work in a nursing home. But at 50, I have different ambitions, and working in a nursing home is fine. (Latvian nurse 4)

Over time, lack of recognition or opportunities to practise their skills could result in deskilling of migrant nurses (Newton et al. 2012). Widding Isaksen (2012) finds that Norwegian workplaces do not recognize the skills that Latvian nurses have acquired in Latvia. This has been a source of frustration, not least among those with special competence. In our interviews, the Latvian nurses rarely raised the issue of de-skilling as such, and appeared reluctant to reveal their attitudes and feelings on the topic. However, one nurse with more than 20 years' experience as a hospital nurse was quite outspoken in her worries about de-skilling:

I could inject even two-week-old infants; now I'm not sure of myself anymore. When a skill isn't used regularly, it disappears. My experience [...] is not gone, however, the practical work is getting lost. Nursing homes remain nursing homes - a small part of nurses’ work. Feeding, changing nappies, putting to bed. (Latvian nurse 8)

By contrast, several Latvian nurses spoke openly about feeling recognised, valued as a person, and 'seen' by their employers in Norway:

I'm glad that nurses have such independence [in Norway]. [...] Of course, you get asked to do everything, and you feel guilty and responsible about everything, but I like feeling appreciated. The person, the employee, is valued here. This isn't felt so directly in Latvia. (Latvian nurse 6)

They feel that the nursing profession is undervalued in Latvia, economically and in policymakers' rhetoric, as well as in the attitudes of patients and society in general.

Home-care and nursing homes often want to employ Latvian nurses directly after they have served their agency contracts, and may even express interest in buying nurses out of their agency agreements. Personnel shortages and the fact that direct employment is cheaper can explain this, but it also reflects recognition of the skills and efforts of these nurses. According to some Latvian nurses, care of the elderly is much better in Norway than in 
Latvia. The equipment and technical aids are better, and nursing involves more talking and psychological comfort. In this regard, the nurses gain new professional experience, but to what extent this compensates for possible feelings of downgrading and de-skilling is not clear.

Also the Swedish nurses do not mention occupational downgrading and de-skilling. In Norway, most of them find work in the hospital sector, where they get to use their medicinal and technological expertise. Higher wages make them feel more valued in Norway than in Sweden (Kiil and Knutsen 2016). As with the Latvian nurses, some are surprised that registered nurses in Norway do everything from medical care to patient hygiene - in Latvia and Sweden, auxiliary nurses and nursing assistants do the work related to personal care. The nurses do not speak negatively about the personal-care element of nursing as such, but former hospital nurses who feel stuck in the nursing-home sector may consider it part of a broader process of de-skilling.

That Norwegian nurses tend to speak pleasantly with patients and colleagues, was mentioned by the Latvian nurses as something positive, but also challenging. Some studies (e.g. Baltic Institute of Social Science 2016; Lember and Nool 2012) indicate that Latvian health care personnel at all levels devote insufficient attention to communicating with patients and awareness of their psychological wellbeing. This is widely explained by personnel shortages, work overloads and that nurses have to work long hours to earn an acceptable wage. Patients in Norwegian hospitals might perceive Baltic nurses as rather harsh, according to an employer in hospital 1. In this perspective, practice in Norway could be a way to augment nursing skills. However, the nurses in our study say they feel pressured to live up to the values and expectations at Norwegian workplaces:

Here [in Norway] [... ] you always have to smile and talk to them... In Latvia, with the labour shortage, you had to do everything very quickly. (Latvian nurse 2)

At work, you can't show that you are stressed out or anything like that. You have to be like those penguins from Madagascar - always smiling and waving. (Latvian nurse 3) The animation film 'Penguins of Madagascar' is very popular among Latvian children, but this statement refers to more than just smiling and waving. The Penguins of Madagascar smile and wave when they have thoughts they want to keep secret from others. To outsiders, they are just 'cute and cuddly', an analogy of the self-restraint that the nurses feel they have to practice to be accepted for their positions.

Greater autonomy for nurses in Norwegian workplaces compared to Latvia entails new responsibilities, and some Latvian nurses find it very challenging to work independently of 
doctors. Latvian nurse 4 noted the huge responsibility involved in assessing patients, and for instance predicting a possible heart attack. New ways of practising their work sometimes bring feelings of being an outsider. According to Latvian nurse 11, Norwegians practice nursing their way, but this way of working is not always acceptable to Eastern Europeans. However, they stand by quietly and do what they are expected to, even it may feel ‘completely topsy-turvy’. Hard work, self-restraint and acceptance like this are exactly what is required in the second layer of double control (Gottfried 1991).

Latvian nurses sometimes have suspicions about what might be said behind their back. Some mentioned the patient reporting system, and the system for reporting deviations from normal practice. The intention is primarily to learn from mistakes, so as to enhance patient safety, but matters like satisfactory staffing, competence, equipment, routines, etc. are also documented (Sykepleien 2015). Latvian nurse 2 spoke of 'deviation reports' as 'piles of complaints'. Also the other nurses appeared somewhat worried about making mistakes that might get reported. The reporting system seems to create feelings of being an outsider.

We've been told that we should not take them [the deviation reports] personally, because it is normal for them, and they will not complain to harm someone, but to prevent such things from happening again. We [...] see it a little differently. If something similar happens to us then we'd just get angry and defensive, but they themselves complain about each other and write all kinds of things in those reports. (Latvian nurse 11)

The Swedish nurses appear to have greater self-confidence. When they experience bad working conditions or work environment they often inform their agency, to ensure that they will not have to return to the same place. Some feel that they are most welcome and get easier tasks when they are new to a workplace, whereas others say that as agency nurses or new to a workplace they sometimes have to work harder than the permanent staff - but this they attribute to the personality of individual colleagues. Confidence notwithstanding, some Swedish nurses said they feared that if they did not work hard they would get a bad reputation and might not be allowed to return to that workplace or get fewer assignments from the agency, as in Gottfried (1991). They feel grateful for their jobs, and take care not to criticize Norwegian workplace routines, or propose other ways of acting based on their experience from Sweden (Zampoukos et al. 2018). Thus, also the Swedish nurses practise some degree of self-restraint in the workplace stemming from the double control of agency and workplace, which impedes a sense of inclusion. 


\section{The role of language for inclusion and exclusion in the workplace}

Language problems are by far the main concern of the Latvian nurses studied here. They struggle with the Norwegian language, the many local dialects making it even more difficult. Latvian agencies usually provide three to four months of intensive language training. Normally, this involves learning the basics of the official written standard for the Norwegian language and terms used in healthcare. When the nurses pass exams that prove language skills 'at the level necessary for work in Norway', the training is completed. According to the Norwegian Directorate of Health, it is up to the employers to decide precisely what language skills to require from nurses from the European Union and the European Economic Area. One nurse in our study had passed a language test at the common European B2 level (the current requirement for nurses from outside the European Union and European Economic Area); and one had passed the B1 test, which has lower requirements than B2. The others had only passed tests conforming to the minimum level of language skills required to work in the health-sector in Norway.

Most of the Latvian nurses in our study said that the language training they had received was not sufficient, and many of them attempted to continue studying on their own, at home and between shifts. Some got additional language courses paid by the agency, whereas other had to pay for additional courses themselves.

If you come to work and do not speak fluently, no one is going to employ you. How was I with that language - oh, dear God! And I thought - please don't start making mistakes, because sometimes you do not understand. Knowing all this, I think, God, it is real utopia - after four months of [language] courses, to go and work in medicine. Yes, it was only homecare, but still! Their homecare is quite different [from in Latvia] - with injections and bandages - God forbid there is anything you don’t understand. (Latvian nurse 3)

The Latvian nurses are also creative in finding ways to compensate for language difficulties:

In the beginning, for example, I didn't know how to ask what shirt or pullover he wanted to wear. So I just opened the wardrobe and showed him, and asked, 'this one or that one?' It was more difficult to ask what he wanted - then he might say, 'the grey with stripes or buttons'... It is better that I bring him ten pieces and show him each one. That was one way of the situation. (Latvian nurse 7) 
If I can’t explain in Norwegian or can’t find the word, I either use Google Translate or say it in English or draw. No problem, you find a way to do it. (Latvian nurse 1).

In her study from 2004/2005, Widding Isaksen (2012) found that Latvian nurses were granted temporary work licenses for three months until their language skills were satisfactory. During that period, they worked under the supervision of a registered nurse and were paid less than registered nurses. Only one of the nurses in our study mentioned a temporary license. Another, who had recently graduated in Latvia and had problems in her first assignment, explained that she got two-three weeks of training in a new workplace to improve her Norwegian and feel safer in her work. She was pleased with this opportunity, although it involved being monitored by nursing colleagues and getting lower wages. One of the colleagues monitoring her was Latvian. That the two spoke the same language proved to be a great help in getting to know the new workplace. However, another nurse had more serious language problems, and the agency terminated her contract.

Some nurses who worry about their language skills have long experience in nursing. In Norway, they have undergone training periods of up to three days where they get close attention and follow-up from their colleagues - but, as Latvian nurse 8 argued, 'three days are not enough to tackle the language problems, up to a week would be better'.

Lower language requirements in the nursing-home sector than in hospitals, and especially in nursing homes in peripheral areas of Norway can explain why this sector is where most Latvian nurses find work. How long it takes to feel at ease with the language varies - from half a year to five years and still struggling. The nurses in our sample tend to remain in this sector after they have served their agency-contract and have become more fluent in the language. Some stay because they are satisfied with the current workplace and do not want to have to set about proving themselves again; and some still struggle with the language: 'there are so many dialects, and new words pop up everywhere’. (Latvian nurse 5)

Working in nursing homes feels familiar. Explaining what has kept her from working in a hospital, Latvian nurse 8 put it like this: 'Language. Probably, it [shifting to a hospital] is not that bad. But then a big decision has to be made; to move, to look for a new place, with new stresses.' Shifting to hospital work would mean having to struggle again with adapting to a new workplace and finding a new place to live.

Latvian nurse 3 told how she experienced the difference in working for agencies and being directly employed: 
Everything depends on how the company [agency] has presented itself. I have heard both positive and negative [stories]. Naturally, if you are working through the company [agency] and you speak bad Norwegian, scepticism arises. However, if you can speak well enough, then it all disappears.

The worries about what Norwegian colleagues might be saying behind the Latvian nurses' backs and the deviation reports (above) could be attributed to language, in two ways. One is suspicion that negative episodes are being said or written down simply because language problems make it difficult to grasp what is going on. The other concerns worries about making mistakes due to language-related misunderstandings. All this may affect well-being at work and feeling included. Moreover, it takes time to become proficient enough to take part in general social conversations:

If somebody wants to contact me, I answer, but I'm not terribly open. I know how to do the medical stuff; I can talk with a patient as well. Still [after two years], I cannot talk about international problems; then I need to think. (Latvian nurse 4)

While the Norwegian language is the main barrier to more and closer interaction with colleagues, Latvian nurse 8 explained how the situation improves with permanent employment or longer stays. When those you work together with know you are going to stay, 'you are accepted as a colleague'. Interaction with colleagues is important for learning the language:

When you are at work, you speak Norwegian for eight hours and hear all the different dialects in your workplace. So you accommodate [get used to the language, pick up words and learn]. Otherwise, it is impossible. (Latvian nurse 1)

Going to a small town is probably a big plus. Then you are thrown into the Norwegian environment whether you want it or not - but you start to talk. (Latvian nurse 5)

This insecurity or fear of being inadequate at work because of language holds the nurses back from greater interaction with leaders and colleagues (as in O’Neill 2011), and consequently restricts their ability to speak up against unfair treatment.

The types of language barriers that the Latvian nurses report and their ingenuity in coming to terms with them are quite in line with international scholarship on foreign-born nurses (Hull 2016; Jose 2010, Magnusdottir 2005; Marcus et al. 2014, O’Neill 2011). Based on our data, the barriers are likely to have an even greater impact on the experiences of agency nurses due to the pressure for self-constraint that the double control incurs. In 
addition, the relatively short period that the nurses spend in Norway at a time could extend the time it takes to improve their language skills.

Language difficulties have resulted in exclusion from the labour market. They also affect the types of positions and thus work tasks that the nurses get and constrain their professional and social interaction - which in turn might be seen as institutional discrimination (as in Newton et al. 2012; Tuttas 2015). However, unfavourable conditions are not necessarily a result of institutional discrimination if these conditions relate to language problems, as proficiency in the language is crucial to avoid misunderstandings and mistreatment of patients.

\section{Conclusions}

Both the Latvian and Swedish nurses are subject to the double control of the agencies, but the Latvians are more dependent on the agencies. They argue that they do not have the financial means to pay for language training, travel to Norway and accommodation on their own. Because of economic advantages of working in Norway, the Latvians accept sub-optimal employment conditions, like lower wages than in direct employment relationships, being contractually bound to the agency for 1.5-2 years, and no compensation during downtime.

The Latvian nurses want to earn higher wages and pensions in Norway, so they can take better care of their families back home. Most explain that they will not return to Latvia for work, due to the low wages and tough working conditions, but some intend to return once they have a pension. All this gives the Latvian nurses strong incentives to keep working in Norway. They compare their situation with working conditions in Latvia, and find the situation in Norway favourable, with better wages and working conditions. However, there is a real danger of de-skilling, since they often end up working in the nursing-home and homecare sector instead of hospitals. The main reason for this is the long time it takes to acquire the language skills required in the hospital sector.

Some of the Latvian nurses who work below their qualifications do not complain, as in resigned acceptance (Batnitzky and McDowell 2011). However, the Latvian nurses in our sample had only worked in Norway during a period of 0.5 to 5-6 years. Further research is required to examine whether Latvian nurses are 'stuck' - or occupational mobility is blocked - in the lower-status nursing-home sector even after they have achieved greater language competence. If they then apply, but do not get jobs in the hospital sector this could indicate institutional discrimination. 
The Swedish nurses are in high demand in the Norwegian labour market due to the small differences in language and culture. This also makes it easier for them to navigate in the Norwegian labour market and makes them less dependent on the agencies. They obtain higher wages, better working conditions, get work that matches their skill levels and are ready to speak up to the agencies against unfair treatment. If they want to leave the agency, they easily find direct employment. However, both the Latvian and Swedish agency nurses experience the pressure of double control at the workplace level. Together with the lack of continuity that arises when agency nurses are shifted from workplace to workplace, the double control impedes a sense of inclusion in the workplace. The Latvian case shows that language problems and cultural differences add to this problem both as a barrier to social communication and risk of occupational downgrading. Even the better off Swedish agency nurses feel that they have to restrain themselves not to compromise their opportunities to return to the workplace or ruin their reputation with the agencies.

Our findings are in line with existing literature on how language and culture pose and exacerbate challenges of labour market integration (Allan and Westwood 2016, Hull 2016; Primeau et al. 2014). We contribute more nuances to existing literature and expand it: We have shown that there can be large differences in how double control of foreign agency nurses plays out in terms of employment conditions. Furthermore, migrant nurses may appreciate the role of agencies as a channel to labour market participation, an issue we have not seen raised in the literature. Their appreciation may both be a matter economic need as it is for the Latvian agency nurses, and a matter of convenience as it is for the Swedes who experience less impact of the double control.

Discrimination of foreign nurses is often raised in the literature (Batnitzky and McDowell 2011; Larsen 2007; Raghuram 2007; Smith and Macintosh 2007; Tuttas 2015) and language can be a proxy for discrimination (Blackledge 2005; Shohamy 2009). The Latvian nurses are quite open about their language problems and worried because mistakes can affect life and health. They also argue that they feel valued in the Norwegian health sector. This is of course not to rule out that language can be used as a proxy for discrimination when life and health are at stake. Last but not least, resigned acceptance (Batnitzky and McDowell 2011) is a good description of how the Latvian nurses respond to many of their challenges of agency nursing and double control. As a concept, it deserves to encompass more than reactions to institutional discrimination. 


\section{References}

Allan, H.T., Westwood, S. (2016). English language skills requirements for internationally educated nurses working in the care industry: Barriers to UK registration or institutionalised discrimination? Editorial. International Journal of Nursing Studies, 54, $1-4$.

Baltic Institute of Social Science (2016). Qualitative Study on Health System Bottlenecks in Latvia. World Bank. http://www.vmnvd.gov.lv/uploads/files/5746bc728b03e.pdf (accessed September 2017).

Batnitzky, A., McDowell, L. (2011). Migration, nursing, institutional discrimination and emotional/affective labour: ethnicity and labour stratification in the UK National Health Service. Social \& Cultural Geography, 12(2), 181-201.

Berge, Ø.M., E. Falkum, Trygstad, S.C., Ødegård. A.M. (2011). Skaff oss dem vi trenger. Om arbeidskraftstrategier og forebygging av sosial dumping i helse og omsorg. Fafo-rapport 2011:20. Fafo, Oslo.

Blackledge, A. (2005) Discourse and Power in a Multilingual World. Amsterdam: John Benjamins.

Buchan, J., Jobanputra, R., Gough, P., Hutt R. (2005). Internationally recruited nurses in London. Profile and implications for policy. King’s Fund Working Paper, September. King's Fund, London.

Central Statistical Bureau of Latvia (2017). Average and real monthly wages and salaries http://www.csb.gov.lv/en/statistikas-temas/metodologija/average-and-real-monthlywages-and-salaries-36647.html (accessed October 2017).

De Ruyter, A., Kirkpatrick, I., Hoque, K., Lonsdale, C., Malan, J. (2008). Agency working and degradation of public service employment: The case of nurses and social workers. The International Journal of Human Resources and Management, 19(3), 432-445.

Fangen, K. (2010). Social exclusion and inclusion of young immigrants: presentation of an analytical framework. YOUNG, 18(2), 133-156.

Fangen, K. \& Paasche, E. (2013). Young adults of ethnic minority background on the Norwegian labour market: the interactional co-constrction of exclusion by employers and customers. Ethnicities, 13(5), 607-624.

Gautun, H., Øien, H., Bratt, C. (2016). Underbemanning er selvforsterkende. Konsekvenser av mangel på sykepleiere i hjemmesykepleien og sykehjem. NOVA-report 6/2016. file:///M:/pc/downloads/Web-utgave-NOVA-Rapport-6-16.pdf (accessed October 2017). 
Gottfried, H. (1991). Mechanisms of control in the temporary help service industry. Sociological Forum, 6(4), 699-713.

Gottfried, H. (1992). In the margins: Flexibility as a mode of regulation in the temporary help service industry. Work, Employment and Society 6(3), 443-460.

Hull, M., 2016. Medical language proficiency: a discussion of interprofessional language competencies and potential for language risks. International Journal of Nursing Studies, 54, $158-72$.

Jose, M. M. (2010). Lived experiences of internationally educated nurses in hospitals in the United States of America. International Nursing Review, 58(1), 123-129.

Kiil, M.B. (2015). Midlertidighet som protest: Svenske sykepleiere og det norske arbeidsmarkedet. Master thesis in Human Geography, University of Oslo. ht tp s:// w w w . du o.u io.n o/ h a nd l e/1 0852 / 56 / browse?value=Kiil\%2C+Maiken+Bjer ga\&type=author (Accessed December 2018)

Kiil, M. B., \& Knutsen, H. M. (2016). Agency by exit: Swedish nurses and the 'Not below 24, 000'movement. Geoforum, 70, 105-114.

Larsen, J.A. (2007). Embodiment of discrimination and overseas nurses' career progression. Journal of Clinical Nursing, 16(12), 2187-2195.

Lember, M. and Nool, I. (2012). Changing brain drain to brain circulation: How to secure enough PHC resources in the BSR. Professional Development, EU: Baltic Sea Region Programme.

Lloyd, L., Banerjee, A., Harrington, C., Jacobsen, F., Szebehely, M. (2014). It is a scandal! Comparing the causes and consequences of nursing home media scandals in five countries. International Journal of Sociology and Social Policy. 34(1/2), 2-18.

Magnusdottir, H. (2005). Overcoming strangeness and communication barriers: a phenomenological study of becoming a foreign nurse. International Nursing Review, 52(4), 263-269.

Marcus, K., Short, S., Nardi, B. (2014). 'Hardworkers’: Filipino Nurses’ professional practice in Queensland. Asia and Pacific Journal of Health Management, 9(1), 28-34.

National Nursing Research Unit (2014). Nurse migration from the EU: What are the key challenges? Policy+. https://www.kcl.ac.uk/nursing/research/nnru/policy/by-issuenumber/policy--issue-42.pdf (accessed March 2017).

NAV (2017). Bedriftsundersøkelsen våren 2017 (pdf) The Labour and Welfare Directorate, Oslo (accessed June 2017). 
Newton, S., Pillay, J., Higginbottom, G. (2012). The migration and transitioning experiences of internationally educated nurses: a global perspective. Journal of Nursing Management, 20(4), 534-550.

NSF (2018) Utfordrende å rekruttere sykepleiere. https://www.nsf.no/visartikkel/3741618/17036/Utfordrende-aa-rekruttere-sykepleiere Norwegian Nurses Association (accessed December 2018).

O’Neill, F. (2011). From language classroom to clinical context: The role of language and culture in communication of nurses using English as a second language. A thematic analysis. International Journal of Nursing Studies, 48 (9), 1120-1128.

Primeau, M-D, Champagne, F., Lavoie-Tremblay, M. (2014). Foreign-trained nurses' experiences and socioprofessional integration. Best Practices. An integrative literature review. The Health Care Manager, 33(3), 245-253.

Raghuram, P. (2007). Interrogating the language of integration: the case of internationally recruited nurses. Journal of Clinical Nursing, 16(12), 2246-2251.

Shohamy, E. (2009). Language tests for immigrants: Why language? Why tests? Why citizenship? In: Hogan-Brun, G., Mar-Molinero, C. and Stevenson, P. (ed.) Discourses on Language and Integration, Amsterdam: John Benjamins, 45-59.

Skjøstad, O., Hjemås, G, Beyrer, S. (2017). 1 av 5 nyutdanna sykepleiere jobber ikke helsetjensten. https://www.ssb.no/helse/artikler-og-publikasjoner/1-av-5-nyutdannasykepleiere-jobber-ikke-i-helsetjenesten (accessed November 2017).

Smith, P., Mackintosh, M., (2007). Profession, market and class: nurse migration and the remaking of division and disadvantage. Journal of Clinical Nursing, 16(12), 2213-2220.

Statistics Norway (2016). Helse- og sosialpersonell 2015, 4. kvartal. https://www.ssb.no/arbeid-og-lonn/statistikker/hesospers/aar/2016-06$\underline{27 \text { ?fane }=\text { tabell\&sort=nummer\&tabell }=270653}$ (accessed March 2017).

Statistics Norway Databank (2017). Wages nurse, wages specialist nurses.

https://www.ssb.no/statistikkbanken/SelectVarVal/Define.asp?MainTable=NaerHelseYrk2\&

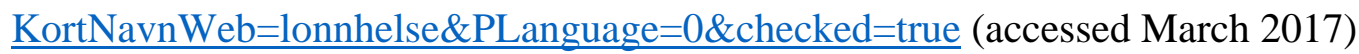

Sykepleien (2015). Liten nytte av å melde avvik. https://sykepleien.no/2015/03/1-av-2-serikke-nytten-av-melde (accessed March 2017).

Tailby, S. (2005). Agency and bank nursing in the UK National Health Service. Work, Employment and Society, 19(2), 369-389. 
Tuttas, C.A. (2015). Perceived racial and ethnic prejudice and discrimination experiences of minority migrant nurses: A literature review. Journal of Transcultural Nursing, 26(5), 514-520.

Widding Isaksen, L. (2012). Transnational spaces of care: migrant nurses in Norway. Social Politics, 19(1), 58-77.

Yin, R.K. (2014). Case Study Research: Design and Methods. $5^{\text {th }}$ ed. Los Angeles: Sage.

Young, A., Temple, B. (2014). Approaches to Social Research: The Case of Deaf Studies. New York: Oxford University Press.

Zampoukos, K., Knutsen, H. M., Kiil, M. B., \& Olofsdotter, G. (2018). Mobile with an agency: negotiating the spatiotemporalities of the temp migrant worker. Geoforum, 93, 4047. 